\title{
Do Patients Taking Warfarin Experience Delays to Theatre, Longer Hospital Stay, and Poorer Survival After Hip Fracture?
}

\author{
John E. Lawrence MA, MB, BChir, MRCS, Daniel M. Fountain BSc, \\ Duncan J. Cundall-Curry MBBS, MRCS Dip Clin Ed, \\ Andrew D. Carrothers MBChB, FRCS (Tr\&Orth)
}

Received: 26 April 2016/Accepted: 22 August 2016/Published online: 1 September 2016

(c) The Author(s) 2016. This article is published with open access at Springerlink.com

\begin{abstract}
Background Patients sustaining a fractured neck of the femur are typically of advanced age with multiple comorbidities. As a consequence, the proportion of these patients receiving warfarin therapy is approximately $10 \%$. There are currently few studies investigating outcomes in this subset of patients.

Questions/purposes The purpose of this study was to assess the association between warfarin therapy and time to surgery, length of hospital stay, and survival in patients sustaining a fractured neck of the femur.
\end{abstract}

Each author certifies that he, or a member of his immediate family, has no funding or commercial associations (eg, consultancies, stock ownership, equity interest, patent/licensing arrangements, etc) that might pose a conflict of interest in connection with the submitted article.

All ICMJE Conflict of Interest Forms for authors and Clinical Orthopaedics and Related Research ${ }^{\mathbb{B}}$ editors and board members are on file with the publication and can be viewed on request.

Each author certifies that his institution approved the human protocol for this investigation, that all investigations were conducted in conformity with ethical principles of research, and that informed consent for participation in the study was obtained. This work was performed at Addenbrooke's Hospital, Cambridge, UK.

Electronic supplementary material The online version of this article (doi:10.1007/s11999-016-5056-0) contains supplementary material, which is available to authorized users.

J. E. Lawrence ( $₫)$, D. J. Cundall-Curry, A. D. Carrothers Department of Trauma and Orthopaedics, Addenbrooke's Hospital, Hills Road, Cambridge CB2 0QQ, UK e-mail: j1507@cam.ac.uk

D. M. Fountain

School of Clinical Medicine, University of Cambridge,

Cambridge, UK
Methods Data for 2036 patients admitted to our center between July 2009 and July 2014 with a fractured neck of the femur were extracted from the National Hip Fracture Database. Fifty-seven patients received no surgical treatment and were excluded from analysis. Multivariable ordinary least squares regression was performed to test the association between warfarin treatment on time to surgery and length of stay, and Cox proportional hazards to test followup survival. Variables included in the regression model were age, sex, American Society of Anesthesiologists (ASA) score, admission Abbreviated Mental Test Score (AMTS), fracture type, operation type, and premorbid Work Ability Index (WAI). One hundred fifty-two of 1979 surgically treated patients $(8 \%)$ were receiving warfarin therapy at the time of admission.

Results After controlling for age, sex, ASA score, AMTS, fracture type, operation type, and WAI, we found that patients taking warfarin were less likely to go to surgery by 36 hours (odds ratio [OR], 0.20; 95\% CI, 0.14-0.30), and less likely to go to surgery by 48 hours (OR, $0.17 ; 95 \% \mathrm{CI}$, 0.11-0.24). Patients taking warfarin had a longer length of stay (median, 15 days; interquartile range [IQR], 12-22 days) compared with patients not taking warfarin (median, 13 days; IQR, 9-20 days; $\mathrm{p}<0.001$ ). Survival analysis to June 2015 showed a higher mortality for patients taking warfarin (12-month survival, $66 \%$ vs $76 \%$; hazard ratio, 1.57; 95\% CI, 1.21-2.04; $\mathrm{p}<0.001)$.

Conclusions After controlling for multiple prognostic factors such as age, ASA score, AMTS, and WAI, warfarin therapy at the time of injury is associated with increased time to surgery, length of stay, and decreased survival. This study highlights the need to view warfarin therapy as a 'red flag' in patients presenting with a fractured neck of the femur. Preoperatively, prompt warfarin reversal together 
with adequate investigation and optimization of the patient should ensure timely, safe surgery. Early involvement of the anesthesia team should ensure an appropriate level of postoperative care for these patients.

Level of Evidence Level III, therapeutic study

\section{Introduction}

Hip fractures account for the majority of orthopaedic trauma in the United Kingdom (UK), with more than 64,000 cases in England, Wales, and Northern Ireland in 2014 [20]. The condition often affects elderly patients with multiple comorbidities and consequently has been shown to have poor clinical outcomes, with mortality at 12 months as much as $36 \%[1,4]$. In the United States, at least 250,000 people are hospitalized with hip fractures annually [6]. This global public health problem is expected to worsen, with sharp increases in the number of hip fractures forecast for the next generation [18]. Despite focus on improving the care of these patients, postinjury mortality remains stubbornly high [11].

Patients who sustain fragility fractures of the hip often have concurrent comorbidities, some of which require anticoagulation with warfarin. Between $7.8 \%$ and $10.3 \%$ of all patients admitted with these fractures are receiving long-term warfarin therapy, which produces a coagulopathic state as expressed by increased International Normalized Ratio (INR) [8, 9, 25]. This coagulopathy must be reduced or eliminated before surgery can safely be performed. The time taken to achieve a safe INR together with the presence of multiple comorbidities has the potential to delay surgical treatment, which conflicts with policy initiatives (such as the 2010 'Best Practice Tariff' in the UK) that aim to improve patient outcomes by reducing delays in hip fracture surgery to less than 48 or 36 hours $[5,19]$. Few studies have investigated the degree to which warfarin therapy is associated with delays to surgery $[2,7,8,16]$, and the degree to which such warfarin-associated care delays are associated with length of stay and mortality has not been reported, to our knowledge.

We sought to determine whether a patient's use of warfarin at the time of admission for a femoral neck fracture was associated with (1) time to hip-fracture surgery, (2) length of hospital stay, and (3) survival in patients sustaining a fractured neck of the femur.

\section{Patients and Methods}

This retrospective study is reported in accordance with the STROBE statement for cohort studies. Data for 2036 consecutive patients admitted to a tertiary referral center with fragility fracture of the femoral neck between July 2009 and July 2014 were extracted from the National Hip Fracture Database. Fifty-seven patients received no surgical treatment and were excluded from analysis. One hundred fifty-two of 1979 surgically treated patients $(8 \%)$
Fig. 1 The flow diagram shows the selection of patient data for our study.

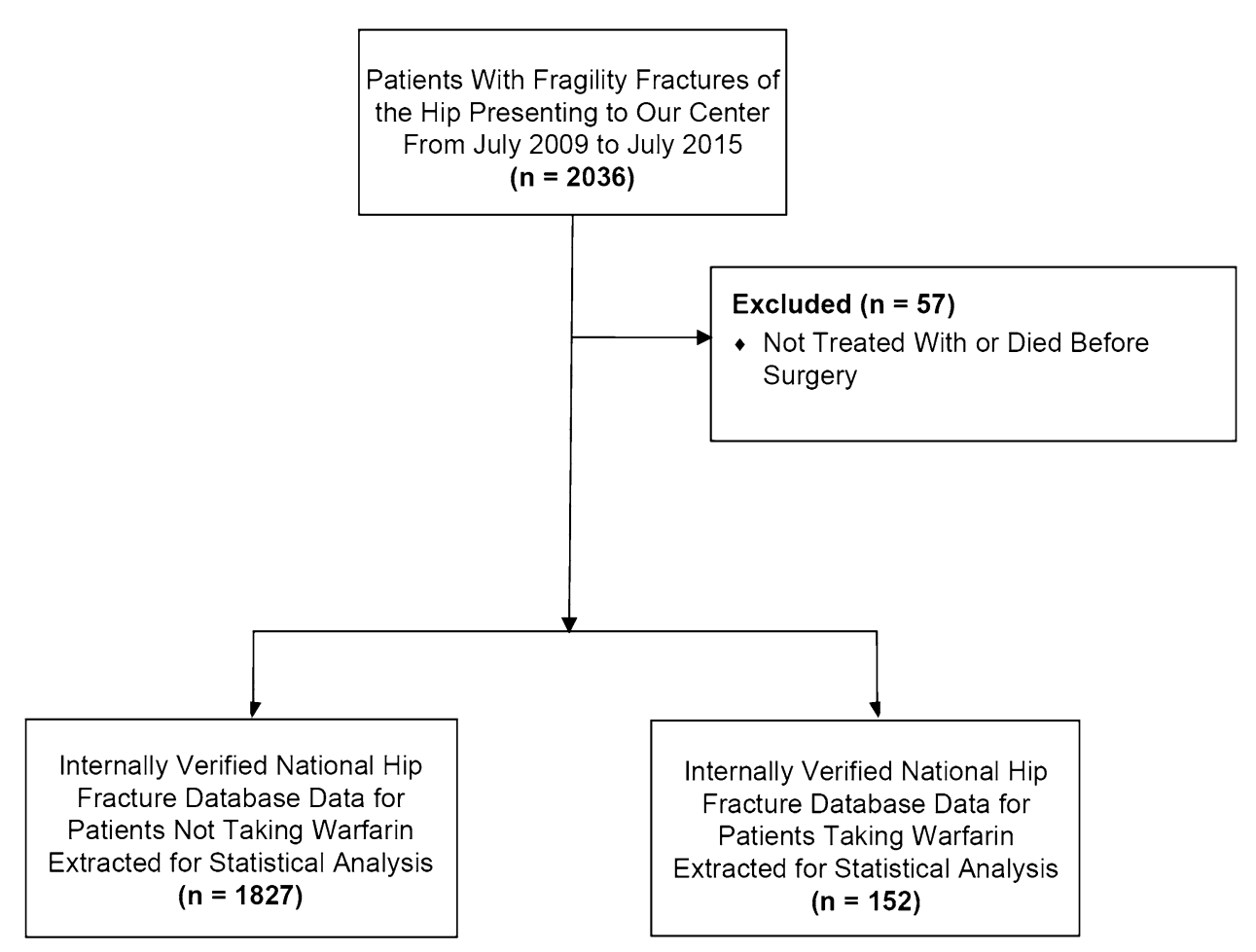


were receiving warfarin therapy at the time of admission (Fig. 1). Internally verified data were collected on the sex, age, abbreviated mental test score (AMTS), premorbid work ability index (WAI), American Society of Anesthesiologists (ASA) grade, fracture type (intracapsularundisplaced, intracapsular-displaced, intertrochanteric, subtrochanteric, other), operation type (internal fixation, hemiarthroplasty, or THA), and time to surgery (Table 1). Warfarin treatment status and admission INR were collected from digital patient records and laboratory reporting

Table 1. Sample description for patients taking and not taking warfarin

\begin{tabular}{|c|c|c|c|}
\hline Measure & $\begin{array}{l}\text { Taking } \\
\text { warfarin }\end{array}$ & $\begin{array}{l}\text { Not taking } \\
\text { warfarin }\end{array}$ & Total \\
\hline Number of patients (\%) & $152(8)$ & $1827(92)$ & 1979 (100) \\
\hline $\begin{array}{l}\text { Age, years (median, } \\
\text { IQR) }\end{array}$ & $84(80-88)$ & $85(79-90)$ & $85(79-90)$ \\
\hline Male, number (\%) & $56(37)$ & 525 (29) & $581(29)$ \\
\hline AMTS, median (IQR) & $8(6-10)$ & $8(4-10)$ & $8(5-10)$ \\
\hline \multicolumn{4}{|l|}{ Fracture type, number (\%) } \\
\hline $\begin{array}{l}\text { Intracapsular- } \\
\text { undisplaced }\end{array}$ & $15(10)$ & $164(9)$ & $179(9)$ \\
\hline $\begin{array}{l}\text { Intracapsular- } \\
\text { displaced }\end{array}$ & $82(54)$ & $883(48)$ & 965 (49) \\
\hline Intertrochanteric & $45(30)$ & $662(36)$ & 707 (36) \\
\hline Subtrochanteric & $10(7)$ & $114(6)$ & $124(6)$ \\
\hline Other & $0(0)$ & $4(0)$ & $4(0)$ \\
\hline \multicolumn{4}{|l|}{ ASA grade*, number $(\%)$} \\
\hline 5 & $1(1)$ & $0(0)$ & $1(0)$ \\
\hline 4 & $16(11)$ & $170(9)$ & $186(9)$ \\
\hline 3 & $91(60)$ & $932(51)$ & $1023(52)$ \\
\hline 2 & $38(25)$ & $651(36)$ & $689(35)$ \\
\hline 1 & $3(2)$ & $56(3)$ & $59(3)$ \\
\hline \multicolumn{4}{|c|}{ Operation type, number (\%) } \\
\hline Femoral screw & $72(47)$ & $921(50)$ & $993(50)$ \\
\hline Hemiarthroplasty & $79(52)$ & $840(46)$ & $919(46)$ \\
\hline THA & $1(1)$ & $66(4)$ & $67(3)$ \\
\hline \multicolumn{4}{|l|}{ Time to surgery } \\
\hline Median hours (IQR) & $46(29-66)$ & $24(19-40)$ & $25(19-41)$ \\
\hline $\begin{array}{l}<36 \text { hours, number } \\
(\%)\end{array}$ & $46(30)$ & $1290(71)$ & $1336(68)$ \\
\hline $\begin{array}{l}<48 \text { hours, number } \\
(\%)^{* *}\end{array}$ & $82(54)$ & $1594(87)$ & $1676(85)$ \\
\hline $\begin{array}{l}\text { Length of stay, median } \\
\text { days (IQR) }\end{array}$ & $15(12-22)$ & $13(9-20)$ & $13(9-20)$ \\
\hline \multicolumn{4}{|l|}{ Survival, number (\%) } \\
\hline 30-day & $138(91)$ & $1732(95)$ & $1870(95)$ \\
\hline 6-month & $115(76)$ & $1500(82)$ & $1615(82)$ \\
\hline 12-month & $101(66)$ & $1395(76)$ & $1496(76)$ \\
\hline
\end{tabular}

*American Society of Anesthesiologists (ASA) grade was missing for 21 patients; $\mathrm{IQR}=$ interquartile range; $\mathrm{AMTS}=$ Abbreviated Mental Test Score; ** includes patients operated on in $<36$ hours. systems manually. Time to surgery was analyzed as a continuous variable and with specific thresholds to evaluate the potential association between warfarin treatment and time to surgery, including the likelihood of having surgery before the UK's Best Practice Tariff ( $<36$ hours) [13] and achieving surgery before a known prognostic time suggested by others as important $(<48$ hours $)$ [3, 14, 21, 22, 28]. Finally, subgroup analysis was performed on patients with an INR above and below 2.5 to assess the association between INR value and outcome. A total of 135 patients were included (Fig. 2). Median INR was 2.3 (interquartile range [IQR], 2.3-9.0). Of these, 61 patients presented with an INR less than 2.5 , with 74 patients presenting with an INR greater than this value. Equivalent analyses were performed to the whole cohort of patients included in this study. Discrete groupings were used instead of INR as a quantitative variable attributable to the limited sample size $(n=135)$. Followup analyses were performed to July 2015.

\section{Statistical Analysis}

Initially, a demographic analysis was done to present key characteristics of the cohort acquired. Variables were analyzed in a multivariable ordinary least squares regression for length of stay and the time to surgery, a logistic regression for the specific time to surgery cutoffs of less than 36 hours and less than 48 hours, and a Cox proportional hazards model for survival. Odds ratios (OR) and 95\% CIs were calculated for logistic regression results and hazard ratios, and $95 \%$ CIs for the Cox proportional hazards model results. Age was modeled using restricted cubic splines. Categorical and nominal variables were modeled as factors. Significance threshold for all variables and interaction terms was set at a probability less than 0.05. All

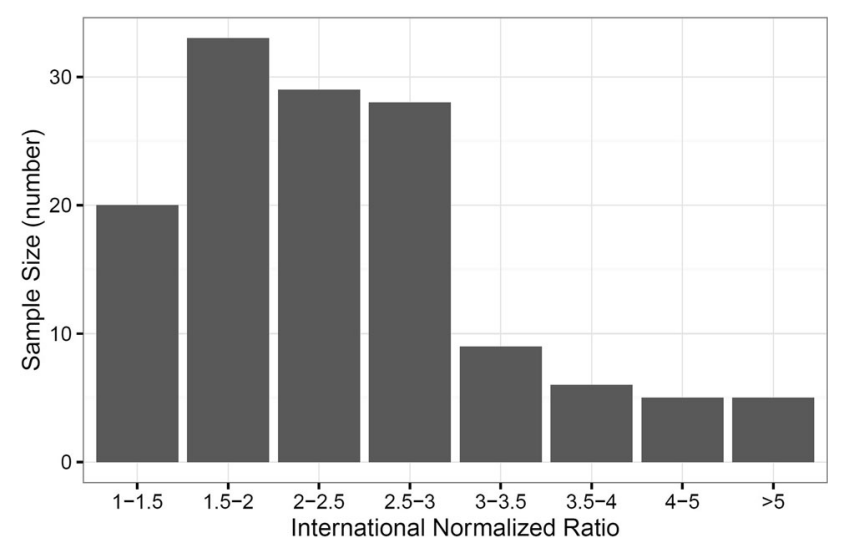

Fig. 2 The graph shows the distribution of admission international normalized ratio where available for the cohort of patients taking warfarin at the time of admission for hip fracture. 
analyses were conducted using the rms package in $\mathrm{R}$ version 3.2.1 [12, 15]. Graphic production was completed using the ggplot2 package in R, version 3.2.1 [27].

The project was approved by and registered with the center's quality improvement team. The National Hip Fracture Database is a national audit in the UK approved by the National Health Service (NHS) England Health Research Authority (HRA) Confidentiality Advisory Group.

\section{Results}

Time to Surgery

After controlling for sex, age, AMTS, WAI, ASA grade, fracture type, and operation type, patients taking warfarin went to surgery later than those not treated with warfarin (Table 2) ( $f=86.8 ; p<0.001)$. Results were consistent when analyzing time-interval thresholds; patients taking warfarin were less likely to go to surgery by 36 hours (OR, $0.20 ; 95 \%$ CI, $0.14-0.30$ ) and less likely to go to surgery by 48 hours (OR, 0.17 ; 95\% CI, 0.11-0.24). Median time to surgery was substantially higher in patients treated with warfarin (median, 46 hours; IQR, 29-66) compared with patients not treated (median, 24 hours; IQR, 19-40). A higher INR did not mean patients were less likely to go to surgery (Supplemental Table 1 [ $\mathrm{f}=0.3 ; \mathrm{p}=0.576$ ]. Supplemental material is available with the online version of $C O R R^{\circledR}$ ).

\section{Length of Stay}

After controlling for sex, age, AMTS, WAI, ASA score, fracture type, and operation, length of stay was found to be increased in patients treated with warfarin (Table 3)
( $\mathrm{f}=13.05 ; \mathrm{p}<0.001)$. Patients treated with warfarin recorded a median length of stay of 15 days (IQR, 12-22 days) compared with 13 days (IQR, 9-20 days) for those not treated with warfarin. A higher INR was not associated with greater length of stay (Supplemental Table 2 $[\mathrm{f}=0.07 ; \mathrm{p}=0.787]$. Supplemental material is available with the online version of $C O R R^{\circledR}$ ).

\section{Survival}

After controlling for age, sex, ASA score, AMTS, WAI, fracture type, and operation, treatment with warfarin was found to be associated with reduced survival with time (chi square $=12.7 ; \mathrm{p}<0.001)($ Table 4$)$. The hazard ratio for warfarin treatment was 1.57 (95\% CI, 1.21-2.04). Unadjusted survival was lower throughout followup for patients taking warfarin (chi square $=9.9 ; p=0.002$ ) (Fig. 3). A higher INR was not associated with reduced followup survival (Supplemental Table 3 [chi square $=0.1, \mathrm{p}=$

Table 3. Multivariable regression results showing factors related to length of stay

\begin{tabular}{llrr}
\hline Factor & df & \multicolumn{1}{c}{ f } & p value \\
\hline Sex & 1 & 23.49 & $<0.001$ \\
Age & 4 & 3.53 & 0.007 \\
AMTS & 1 & 44.32 & $<0.001$ \\
ASA grade & 3 & 12.03 & $<0.001$ \\
Fracture type & 4 & 2.84 & 0.023 \\
WAI & 8 & 1.98 & 0.045 \\
Operation type & 2 & 2.23 & 0.108 \\
Warfarin & 1 & 13.05 & $<0.001$ \\
\hline
\end{tabular}

AMTS = Abbreviated Mental Test Score; ASA = American Society of Anesthesiologists; WAI = Work Ability Index.

Table 2. Multivariable regression results showing factors related to time to surgery

\begin{tabular}{|c|c|c|c|c|c|c|c|c|c|}
\hline \multirow[t]{2}{*}{ Factor } & \multicolumn{3}{|c|}{ Time to surgery (hours) } & \multicolumn{3}{|c|}{$<36$ hours } & \multicolumn{3}{|c|}{$<48$ hours } \\
\hline & $\mathrm{df}$ & $\mathrm{f}$ & $\mathrm{p}$ value & df & Chi square & $\mathrm{p}$ value & $\mathrm{df}$ & Chi square & $\mathrm{p}$ value \\
\hline Sex & 1 & 4.9 & 0.028 & 1 & 0.5 & 0.484 & 1 & 1.5 & 0.219 \\
\hline Age & 4 & 1.6 & 0.161 & 4 & 7.0 & 0.138 & 4 & 2.0 & 0.741 \\
\hline AMTS & 1 & 3.7 & 0.054 & 1 & 6.9 & 0.009 & 1 & 4.4 & 0.037 \\
\hline WAI & 8 & 0.9 & 0.522 & 8 & 11.5 & 0.177 & 8 & 1.3 & 0.996 \\
\hline ASA grade & 4 & 7.6 & $<0.0001$ & 4 & 10.1 & 0.039 & 4 & 18.6 & 0.001 \\
\hline Fracture type & 4 & 2.3 & 0.059 & 4 & 2.4 & 0.656 & 4 & 2.9 & 0.575 \\
\hline Operation type & 2 & 5.2 & 0.006 & 2 & 11.2 & 0.004 & 2 & 12.0 & 0.002 \\
\hline Warfarin & 1 & 86.8 & $<0.0001$ & 1 & 69.9 & $<0.0001$ & 1 & 89.1 & $<0.001$ \\
\hline
\end{tabular}

AMTS $=$ Abbreviated Mental Test Score WAI = Work Ability Index; ASA = American Society of Anesthesiologists. 
Table 4. Cox proportional hazards survival model

\begin{tabular}{llrr}
\hline Factor & df & Chi square & p value \\
\hline Sex & 1 & 35.0 & $<0.001$ \\
Age & 4 & 31.5 & $<0.001$ \\
AMTS & 1 & 58.0 & $<0.001$ \\
WAI & 8 & 27.9 & 0.001 \\
ASA grade & 4 & 101.5 & $<0.001$ \\
Fracture type & 4 & 12.2 & 0.016 \\
Operation type & 2 & 6.1 & 0.047 \\
Time to surgery & 1 & 0.0 & 0.912 \\
Warfarin & 1 & 12.7 & $<0.001$ \\
\hline
\end{tabular}

AMTS = Abbreviated Mental Test Score; WAI = Work Ability Index; ASA = American Society of Anesthesiologists.

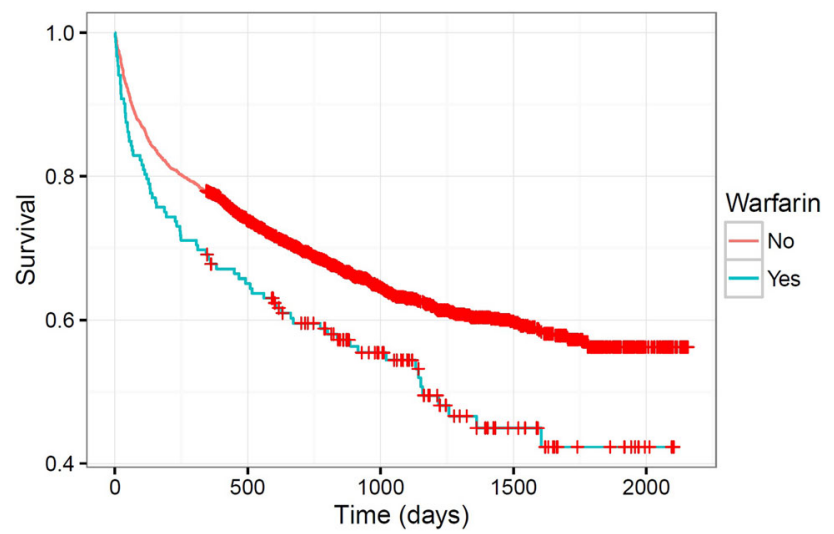

Fig. 3 The survival curves show the effect of warfarin treatment status on survival.

0.767]. Supplemental material is available with the online version of $C O R R^{\circledR}$ ).

\section{Discussion}

Fractures of the femoral neck are a rapidly growing international public health problem. Many of the patients who sustain this injury are elderly with multiple comorbidities, some of which require the use of warfarin therapy. The resultant coagulopathy together with the presence of these comorbidities has the potential to delay treatment and subsequently affect outcomes. We found that in our patient population, after controlling for age, sex, ASA score, AMTS, WAI, fracture type, and operation, that warfarin therapy is associated with increased time to surgery, length of stay, and decreased survival.

This study used data from the National Hip Fracture Database together with the digitally stored components of hospital patient records. Although this approach was practical for the large number of patients involved and allowed a wide range of relevant information to be gathered, it was not exhaustive in its level of detail. Some relevant information was contained only in the patient's "paper" hospital notes, the majority of which are retained at a storage facility not in our center and with very limited access for research purposes. In particular, we were unable to control more precisely for comorbidity in our analysis. Although our study controlled for ASA grade, which has been shown to accurately reflect medical comorbidity and the likelihood of medical complications and mortality after surgery, this does not allow accurate conclusions to be drawn regarding the causes of differing outcomes between the two groups $[10,17]$. Similarly, our data did not contain detailed information regarding the reasons for delays to the operating room. There are several possible difference between the two groups in this regard. The most common indication for warfarin therapy in this group of patients is atrial fibrillation $(83 \%)$, followed by thromboembolic disease $(18 \%)$, and mechanical heart valve (5\%), with approximately $7 \%$ having multiple indications [9]. These comorbidities may cause delays in time to the operating room owing to the time needed to appropriately investigate and optimize the patient before administration of anesthesia. Similarly, the time taken to reverse the warfarininduced coagulopathy using reversal agents in these patients may be a cause of delay. Future studies investigating the cause of these differences would need detailed analysis of drug cards and patient notes that were not possible for this study. This will be aided by the use of digital recordkeeping, which is becoming increasingly popular across the UK. Although our study involves a relatively large cohort of 1979 patients, the number taking warfarin was comparatively small. This did not allow for detailed subgroup analysis, which would have enabled us to draw more detailed conclusions regarding the relationship between admission INR and clinical outcome. 
We found that after controlling for age, sex, ASA score, AMTS, WAI, fracture type, and operation type, warfarin therapy was associated with increased time to surgery. This delay has been reported in previous studies [7, 8, 16, 24], although our study is the first, to our knowledge, showing the same association after regression analysis using these prognostic factors. Ryan et al. [21] conducted a study with more than two million patients sustaining a fractured neck of the femur and reported that a time to the operating room in excess of 48 hours resulted in higher mortality, with an OR of 1.13 for the delayed group after controlling for multiple prognostic factors including comorbidity. They also showed this risk increased with time, with patients who had surgery more than 3 days after admission having a substantially increased risk of death (OR, 1.33). Our study is the most comprehensive to date to show association between warfarin therapy and delays to the operating room, and therefore should highlight the need to prevent any avoidable preoperative delays in these patients. Early warfarin reversal together with adequate investigation and optimization of these more complex patients could ensure timely, safe surgery $[2,7-9,23,26]$.

Patients receiving warfarin at the time of hospital admission for femoral neck fracture had longer lengths of hospital stay. Previous studies have come to differing conclusions regarding this matter. Ranhoff et al. [16], in a 2011 study of 1192 patients with hip fracture, found longer length of stay for warfarin users compared with nonusers. Conversely, Eardley et al. [8], in a [2014 study of 1024 patients, showed no association between length of stay and the use of warfarin at the time of admission for hip fracture. Our study differs from both of these in that we have controlled for age, sex, ASA score, AMTS, WAI, fracture type, and operation type in our analysis. Our study therefore provides the most robust evidence to date that warfarin users experience longer hospital stays after hip fracture.

We found that patients taking warfarin before their hip fractures were more likely to die during the 12 months after hip-fracture surgery. This is the first study, to our knowledge, to show poorer survival in this group of patients. This should encourage clinicians to treat warfarin therapy as a 'red flag' in patients sustaining a fractured neck of the femur and ensure all necessary steps are taken to ensure early surgery, involvement of all the appropriate medical teams, and appropriate levels of postoperative care.

Our study showed an association between warfarin therapy at the time of admission for hip fracture and outcome as measured by time to surgery, length of stay, and survival. Clinicians should ensure this complex group of patients receive an appropriate level of postoperative care, with early involvement of the anesthesia team. Warfarin should be recommenced in a timely manner to ensure a therapeutic INR is achieved when the patient is clinically fit for discharge. Further studies should focus on establishing the cause of these poor outcomes and identify areas for improvement in the care of these patients.

Acknowledgments We thank Lizzie Hart (patient safety coordinator for musculoskeletal disease, digestive diseases, cancer, laboratories, and imaging, Addenbrooke's Hospital, Cambridge, UK) for help with ethical approval for this study.

Open Access This article is distributed under the terms of the Creative Commons Attribution 4.0 International License (http://creativecommons. org/licenses/by/4.0/), which permits unrestricted use, distribution, and reproduction in any medium, provided you give appropriate credit to the original author(s) and the source, provide a link to the Creative Commons license, and indicate if changes were made.

\section{References}

1. Abrahamsen B, van Staa T, Ariely R, Olson M, Cooper C. Excess mortality following hip fracture: a systematic epidemiological review. Osteoporos Int. 2009;20:1633-1650.

2. Ahmed I, Khan MA, Nayak V, Mohsen A. An evidence-based warfarin management protocol reduces surgical delay in hip fracture patients. J Orthop Traumatol. 2014;15:21-27.

3. Al-Ani AN, Samuelsson B, Tidermark J, Norling Å, Ekström W, Cederholm T, Hedström M. Early operation on patients with a hip fracture improved the ability to return to independent living: a prospective study of 850 patients. J Bone Joint Surg Am. 2008;90:1436-1442.

4. Brennan (nee Saunders) J, Johansen A, Butler J, Stone M, Richmond P, Jones S, Lyons RA. Place of residence and risk of fracture in older people: a population-based study of over 65year-olds in Cardiff. Osteoporos Int. 2003;14:515-519.

5. British Orthopaedic Association. The Care of Patients With Fragility Fracture. 2007. Available at: http://www.fractures.com/ pdf/BOA-BGS-Blue-Book.pdf. Accessed March 17, 2016.

6. CDC Centers for Disease Control and Prevention. National Hospital Discharge Survey (NHDS), National Center for Health Statistics. Health Data Interactive, Health Care Use and Expenditures. Available at: http://www.cdc.gov/nchs/nhds/index.htm. Accessed July 14, 2016.

7. Diament M, MacLeod K, O'Hare J, Tate A, Eardley W. "Early trigger" intravenous vitamin $\mathrm{K}$ : optimizing target-driven care in warfarinised patients with hip fracture. Geriatr Orthop Surg Rehabil. 2015;6:263-268.

8. Eardley WG, Macleod KE, Freeman H, Tate A. "Tiers of delay": warfarin, hip fractures, and target-driven care. Geriatr Orthop Surg Rehabil. 2014;5:103-108.

9. Gleason LJ, Mendelson DA, Kates SL, Friedman SM. Anticoagulation management in individuals with hip fracture. $J \mathrm{Am}$ Geriatr Soc. 2014;62:159-164.

10. Hackett NJ, De Oliveira GS, Jain UK, Kim JYS. ASA class is a reliable independent predictor of medical complications and mortality following surgery. Int J Surg. 2015;18:184-190.

11. Haleem S, Lutchman L, Mayahi R, Grice JE, Parker MJ. Mortality following hip fracture: trends and geographical variations over the last 40 years. Injury. 2008;39:1157-1163.

12. Harrell FE Jr. Rms: Regression Modeling Strategies. R Package Version 4.2-1. 2014. Available at: http://CRAN.R-project.org/ package $=$ rms. Accessed March 15, 2016.

13. Monitor and NHS England: National tariff payment system 2014/ 15. Available at: https://www.gov.uk/government/publications/ national-tariff-payment-system-2014-to-2015. Accessed August 17, 2016. 
14. Orosz GM, Magaziner J, Hannan EL, Morrison RS, Koval K, Gilbert M, McLaughlin M, Halm EA, Wang JJ, Litke A, Silberzweig SB, Siu AL. Association of timing of surgery for hip fracture and patient outcomes. JAMA. 2004;291:1738-1743.

15. R Development Core Team. R: A Language and Environment for Statistical Computing. R Foundation for Statistical Computing. Vienna, Austria: R Foundation for Statistical Computing; 2008. Available at: http://www.R-project.org/. Accessed March 15, 2016.

16. Ranhoff AH, Martinsen MI, Holvik K, Solheim LF. Use of warfarin is associated with delay in surgery for hip fracture in older patients. Hosp Pract (1995). 2011;39:37-40.

17. Ringdal KG, Skaga NO, Steen PA, Hestnes M, Laake P, Jones JM, Lossius HM. Classification of comorbidity in trauma: the reliability of pre-injury ASA physical status classification. Injury. 2013;44:29-35.

18. Rosengren BE, Karlsson MK. The annual number of hip fractures in Sweden will double from year 2002 to 2050: projections based on local and nationwide data. Acta Orthop. 2014;85:234-237.

19. Royal College of Physicians. Falls and Fragility Fracture Audit Programme: National Hip Fracture Database. Available at: http:// www.nhfd.co.uk. Accessed March 17th 2016.

20. Royal College of Physicians. Falls and Fragility Fracture Audit Programme: National Hip Fracture Database annual report 2015. Available at: http://www.nhfd.co.uk/nhfd/nhfd2015reportPR1. pdf. Accessed March 17th 2016.

21. Ryan DJ, Yoshihara H, Yoneoka D, Egol KA, Zuckerman JD. Delay in hip fracture surgery: an analysis of patient-specific and hospital-specific risk factors. J Orthop Trauma. 2015;29:343348.

22. Shiga T, Wajima Z, Ohe Y. Is operative delay associated with increased mortality of hip fracture patients? Systematic review, meta-analysis, and meta-regression. Can J Anaesth. 2008;55:146-154.

23. Tal A, Rubin G, Rozen N. Treatment with vitamin $\mathrm{K}$ in hip fracture patients receiving warfarin. Isr Med Assoc J. 2013;15:348-351.

24. Tharmarajah P, Pusey J, Keeling D, Willett K. Efficacy of warfarin reversal in orthopedic trauma surgery patients. J Orthop Trauma. 2007;21:26-30.

25. Tran T, Delluc A, de Wit C, Petrcich W, Le Gal G, Carrier M. The impact of oral anticoagulation on time to surgery in patients hospitalized with hip fracture. Thromb Res. 2015;136:962-965.

26. Vitale MA, Vanbeek C, Spivack JH, Cheng B, Geller JA. Pharmacologic reversal of warfarin-associated coagulopathy in geriatric patients with hip fractures: a retrospective study of thromboembolic events, postoperative complications, and time to surgery. Geriatr Orthop Surg Rehabil. 2011;2:128-134.

27. Wickham H. ggplot2: Elegant Graphics for Data Analysis. New York, NY: Springer-Verlag; 2009.

28. Zuckerman JD, Skovron ML, Koval KJ, Aharonoff G, Frankel VH. Postoperative complications and mortality associated with operative delay in older patients who have a fracture of the hip. $J$ Bone Joint Surg Am. 1995;77:1551-1556. 